\title{
Host immune responses after hypoxic reactivation of IFN- $\gamma$ induced persistent Chlamydia trachomatis infection
}

\author{
Stefan Jerchel ${ }^{1}$, Inga Kaufhold ${ }^{1}$, Larissa Schuchardt ${ }^{1}$, Kensuke Shima ${ }^{1}$ and Jan Rupp ${ }^{1,2 *}$ \\ 1 Institute of Medical Microbiology and Hygiene, University of Lübeck, Lübeck, Germany \\ ${ }^{2}$ Medical Clinic III/Infectious Diseases, University Hospital of Schleswig-Holstein, Lübeck, Germany
}

\section{Edited by:}

Nicole Borel, University of Zurich,

Switzerland

Reviewed by:

Nicole Borel, University of Zurich, Switzerland

Alan Paul Hudson, Wayne State University School of Medicine, USA

Robert V. Schoborg, East Tennessee State University, USA

${ }^{*}$ Correspondence:

Jan Rupp, Institute of Medical

Microbiology and Hygiene,

University of Lübeck, Ratzeburger

Allee 160, 23562 Lübeck, Germany

e-mail: jan.rupp@uksh.de
Genital tract infections with Chlamydia trachomatis (C. trachomatis) are the most frequent sexually transmitted disease worldwide. Severe clinical sequelae such as pelvic inflammatory disease (PID), tubal occlusion, and tubal infertility are linked to inflammatory processes of chronically infected tissues. The oxygen concentrations in the female urogenital tract are physiologically low and further diminished $\left(0.5-5 \% \mathrm{O}_{2}\right.$, hypoxia) during an ongoing inflammation. However, little is known about the effect of a low oxygen environment on genital $C$. trachomatis infections. In this study, we investigated the host immune responses during reactivation of IFN- $\gamma$ induced persistent $C$. trachomatis infection under hypoxia. For this purpose, the activation of the MAP-kinases p44/42 and p38 as well as the induction of the pro-inflammatory cytokines IL-1 $\beta, I L-6, I L-8$, and MCP-1 were analyzed. Upon hypoxic reactivation of IFN- $\gamma$ induced persistent $C$. trachomatis infection, the phosphorylation of the p44/42 but not of the p38 MAP-kinase was significantly diminished compared to IFN- $\gamma$ induced chlamydial persistence under normoxic condition. In addition, significantly reduced IL-6 and IL-8 mRNA expression levels were observed for reactivated Chlamydiae under hypoxia compared to a persistent chlamydial infection under normoxia. Our findings indicate that hypoxia not only reactivates IFN- $\gamma$ induced persistent C. trachomatis infections resulting in increased bacterial growth and progeny but also dampens inflammatory host immune signaling responses that are normally observed in a normoxic environment.

Keywords: Chlamydia trachomatis, persistence, hypoxia, reactivation, immune response

\section{INTRODUCTION}

Chlamydia trachomatis (C. trachomatis) is an obligate intracellular pathogen and the most frequent sexually transmitted bacterium worldwide. In the United States $\sim 1.5$ million infections were reported in 2011 (Centers for Disease Control and Prevention, 2012). While most of the infections occur without symptoms, a symptomatic manifestation of urogenital chlamydial infection can be observed in $\sim 30 \%$ of the patients. In a subset of female patients, ascending genital tract infections cause disease such as salpingitis, pelvic inflammatory disease (PID), or tubal infertility (Peipert, 2003; Mardh, 2004). Chlamydial pathology is attributed to severe inflammatory processes leading to scarring and loss of functional epithelial tissue (Peipert, 2003; Mardh, 2004). During the infection, different pro-inflammatory cytokines such as Interleukin (IL)-1, IL-6, and IL-8 are induced and thought to affect the disease outcome (Rasmussen et al., 1997; Hanada et al., 2003; Buchholz and Stephens, 2007; Hvid et al., 2007). Reoccurrence or a chronic infection with C. trachomatis are discussed to be central mediators of disease progression and final outcome (Dean et al., 2000). However, it is not clear whether chlamydial reoccurrence after a symptomatic episode with/without antibiotic treatment occurs mainly due to reinfection transferred from the sexual partner or due to reactivation of persistent $C$. trachomatis from a silent state (Golden et al., 2005; Geisler, 2007). Persistence describes a non-infectious but viable developmental stage. In the in vitro chlamydial persistence models, the infection is characterized by an altered intracellular inclusion morphology that is accompanied by reduced chlamydial progeny and increased cell survival compared to actively replicating pathogens (Hogan et al., 2004). Chlamydial persistence can be induced through various stimuli including interferon- $\gamma($ IFN- $\gamma)$, treatment with sub-inhibitory concentrations of antibiotics or iron depletion (Wyrick, 2010). Although the induction of persistent Chlamydiae has been extensively studied in vitro, data showing persistently infected urogenital tissues in diseased females are still missing, hence characteristics of persistent in vivo urogenital C. trachomatis infections in humans were not observed yet. Regarding this, persistence defining properties are only based on in vitro experiments and might be different in vivo. Persistent chlamydial infection of the urogenital tract in vivo have so far only been shown in a C. muridarum mice infection model (Phillips et al., 2012). Phillips et al. could show a reduced number of infectious Chlamydiae in persistent infection while pre-16s rRNA expression was not changed, indicating a viable but not infectious chlamydial form (Phillips et al., 2012). Further, they could show chlamydial inclusions with abnormal reticulate bodies but without elementary bodies (EBs) via transmission electron microscopy (Phillips et al., 2012). These findings were in line with the observations of in vitro persistence models. 
We and others could show that persistent C. trachomatis are less susceptible to currently available first-line antimicrobials which presumably could result in clinical treatment failures (Reveneau et al., 2005; Phillips et al., 2012; Shima et al., 2013) and might favor C. trachomatis survival within its biological niche thereby inducing chronic infections. In this study, we focused on the IFN- $\gamma$ induced persistence of $C$. trachomatis as the most extensively studied model in the past (Beatty et al., 1993, 1994; Roth et al., 2010). Based on a previous observation that anti-chlamydial activity of IFN- $\gamma$ is reduced in a low oxygen environment allowing persistent Chlamydiae to reactivate and proliferate (Roth et al., 2010), we wondered about the host immune responses that are induced during this process.

\section{METHODS}

\section{EPITHELIAL CELL CULTURE AND C. TRACHOMATIS INFECTION}

A total of $2.5 \times 10^{5}$ HeLa-229 cells were cultured with $5 \mathrm{ml}$ RPMI 1640 (PAA Laboratories, Cölbe, Germany) supplemented with 5\% FBS (PAA Laboratories), $100 \mathrm{mg} / \mathrm{L}$ L-glutamine (PAA Laboratories), $1 \times$ non-essential amino acids (PAA Laboratories) with or without $5 \mathrm{U} / \mathrm{ml}$ IFN- $\gamma$ (Peprotech, Hamburg, Germany) in a 6 -well plate and incubated for $24 \mathrm{~h}$ under normoxia at $37^{\circ} \mathrm{C}$, $20 \% \mathrm{O}_{2}, 5 \% \mathrm{CO}_{2}$. IFN- $\gamma$ was present over the whole experiment. After incubation, HeLa-229 cells were infected with 2 inclusion forming units (IFUs)/cell of $C$. trachomatis serovar D and centrifuged for $60 \mathrm{~min}$ at $700 \times \mathrm{g}$. After $24 \mathrm{~h}$ incubation under normoxia, persistent $C$. trachomatis infected cells were further cultivated either in normoxic or hypoxic incubators $\left(37^{\circ} \mathrm{C}, 2 \% \mathrm{O}_{2}, 5 \%\right.$ $\mathrm{CO}_{2}$ ) (Toepffer Lab Systems, Goeppingen, Germany) for additional 2 and 3 days (d). The medium was exchanged every second day with medium containing $5 \mathrm{U} / \mathrm{mL}$ IFN $-\gamma$. Hypoxic samples were cultivated in preconditioned medium that was incubated under hypoxic conditions for $12 \mathrm{~h}$ before medium exchange.

\section{CHLAMYDIAL RECOVERY}

The burden of infectious $C$. trachomatis EBs after intracellular development under normoxic and hypoxic conditions was determined by titration experiments as described before (Beatty et al., 1993). In brief, infected cell monolayers were harvested and disrupted by glass beads. Disrupted cells including C. trachomatis were inoculated in serial dilutions on confluent HEp2 cell monolayers in DMEM supplemented with $10 \%$ FBS, $100 \mathrm{mg} / \mathrm{L} \mathrm{L}$-glutamine, $1 \times$ non-essential amino acids under normoxia. Development of chlamydial inclusions was analyzed $48 \mathrm{~h}$ post infection (h p.i.) using an anti-Chlamydia-LPS antibody (kindly provided by H. Brade; Research Centre Borstel, Borstel, Germany) together with a secondary FITC-labeled anti-mouse antibody (Dako, Glostrup, Denmark). Recovered C. trachomatis were calculated by observation of 10 high-power fields $(20 \times$ magnification). Infectious progeny under different conditions was determined by calculating the absolute IFUs. All data are the average from seven independent experiments and the error bars represent the standard error of the mean (s.e.m.).

\section{FLUORESCENCE MICROSCOPY}

To analyze C. trachomatis inclusion morphology after 2 and $3 \mathrm{~d}$ infection, C. trachomatis infected cells were grown on coverslips. After fixation with methanol, cells were stained with
FITC-labeled monoclonal anti-Chlamydia-LPS antibody and evans blue (Oxoid, Cambridgeshire, UK) and morphology was analyzed by a fluorescence microscope (Keyence, Osaka, Japan). To determine the inclusion size 10 inclusions/condition from five different experiments (total 50 inclusions/condition) were measured by using the BZ-II-Analyzer (Keyence, Osaka, Japan).

\section{WESTERN BLOT ANALYSIS}

For determination of phospho-p38/-p44/42 (Cell Signaling, Danvers), cells were prepared with western blot lysis buffer (125 mM Tris-HCl pH 7.8, 20\% glycerol, 4\% SDS (sodium dodecyl sulfate), $0.1 \mathrm{M}$ dithiothreitol, bromphenol blue, Sigma Aldrich, St. Louis) at the indicated time points. Samples were analyzed by SDS-Polyacrylamide gel electrophoresis (SDS-PAGE). Afterwards, proteins were transferred to nitrocellulose membranes (Whatman Inc., Florham Park, NJ). Membranes were blocked with TBS $(0.1 \%$ Tween $) / 5 \%$ fat-free skimmed milk and incubated with the respective antibodies. For detection, a horseradish peroxidase-linked anti-mouse IgG antibody (Cell Signaling) and enhanced chemiluminescence substrate (Thermo Fisher Scientific, Rockford, IL) were used. Images were acquired by Fusion FX7 (Vilber Lourmat, Eberhardzell, Germany) and the density of each band was measured by Bio-1D software (Vilber Lourmat). Equal loading and blotting efficiency were verified by an anti- $\beta$-actin antibody and pre-stain marker (Cell Signaling). All data are the average from seven independent experiments and the error bars represent the standard error of the mean (s.e.m.).

\section{ANALYSIS OF mRNA EXPRESSION}

Total RNA was isolated using the NucleoSpin RNA II kit (Macherey-Nagel, Dueren, Germany) and transcribed into cDNA by the First-Strand PCR kit (Roche, Basel, Switzerland). PCR amplification was performed by using the LightCycler Detection System (Roche). Relative quantification of IL- $1 \beta$ (forward TCCCCAGCCCTTTTGTTGA, reverse TTAGAACC AAATGTGGCCGTG), IL-6 (forward CCTTCCAAAGATGGC TGAAA, reverse CAGGGGTGGTTATTGCATCT), IL-8 (forward CCAGGAAGAAACCACCGGA, reverse GAAATCAGGA AGGCTGCCAAG), MCP-1 (forward CATTGTGGCCAAGGAGA TCTG, reverse CTTCGGAGTTTGGGTTTGCTT) mRNA expression was performed against $18 \mathrm{~S}$ rRNA (forward TCAAGAACG AAAGTCGGAGG, reverse GGACATCTAAGGGCATCACA) and normalized to the respective mRNA expression levels in normoxic non-infected cells by using the $2^{-\Delta \Delta C T}$ method (Livak and Schmittgen, 2001). All data are the average from seven independent experiments and the error bars represent the standard error of the mean (s.e.m.).

\section{STATISTICAL ANALYSIS}

Data are indicated as mean \pm s.e.m. Statistical analysis was performed with the tailed, unpaired Student $t$-test. $p$-values $\leq 0.05$ were considered as statistically significant.

\section{RESULTS}

\section{HYPOXIC REACTIVATION OF PERSISTENT C. TRACHOMATIS}

To determine whether IFN- $\gamma$ induced persistent $C$. trachomatis $\mathrm{D}$ could be reactivated in HeLa-229 cells under hypoxia, we 
used the experimental setup displayed in Figure 1. After transfer of persistent $C$. trachomatis in a hypoxic environment $\left(2 \% \mathrm{O}_{2}\right)$, reactivation of chlamydial growth was observed by a significant increase in the inclusion size compared to cultivation under normoxic conditions (Figures 2A-E). In accordance, the amount of recoverable infectious $C$. trachomatis significantly increased after 3 days cultivation in hypoxia, whereas no increase was observed under normoxic conditions (Figure 2F). These observations confirm previous findings of reactivated C. trachomatis L2 in HEp-2 cells (Roth et al., 2010) and indicate that IFN- $\gamma$ treatment under hypoxia is less effective to maintain $C$. trachomatis in a persistent state.

\section{ANALYSIS OF MAP-KINASE p44/42 AND p38 PHOSPHORYLATION IN REACTIVATED C. TRACHOMATIS INFECTION UNDER HYPOXIA}

To further investigate the influence of reactivated C. trachomatis on host cell immune responses under hypoxia, we analyzed the activation of the MAP-kinases p44/42 and p38 (Figure 3) which were described to be activated during productive infection under normoxic conditions. Under normoxic condition, we observed a significantly enhanced accumulation of the phosphorylated p44/42 MAP-kinase upon IFN- $\gamma$ treatment which was not further enhanced in persistently infected cells. Interestingly, the accumulation of the phosphorylated p44/42 MAP-kinase was significantly reduced in IFN- $\gamma$ treated cells with (Figure 3, $3 \mathrm{~d}$ ) or without (w/o) (Figure 3, 2 and 3 d) C. trachomatis infection under hypoxic compared to normoxic conditions. Although hypoxic cultivation slightly enhanced the phosphorylation of p38 in all samples, no significant differences in the activation pattern were observed in IFN- $\gamma$ treated cells w/o C. trachomatis infection. Furthermore, no accumulation of phosphorylated p38 could be observed in normoxic cells treated with IFN- $\gamma$ w/o C. trachomatis infection.

\section{REDUCED PRO-INFLAMMATORY CYTOKINE INDUCTION IN REACTIVATED C. TRACHOMATIS INFECTION UNDER HYPOXIA}

To reveal whether hypoxic reactivation of persistent C. trachomatis is recognized by the host cell and translated into a pro-inflammatory cytokine response, mRNA expression levels of IL-1 $\beta$, IL-6, IL-8, and MCP-1 were analyzed. Under normoxic conditions, IFN- $\gamma$ treatment w/o $C$. trachomatis infection

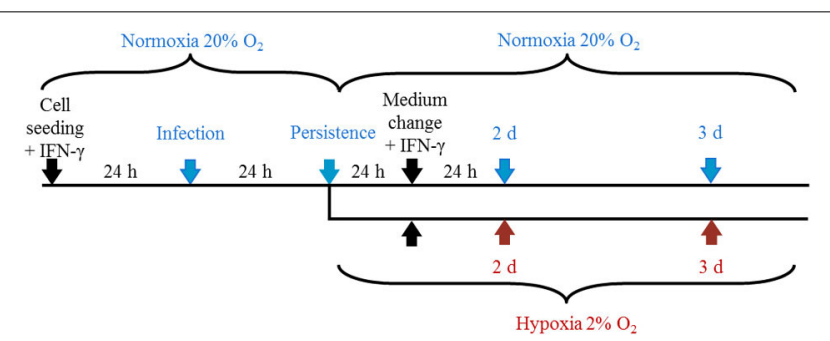

FIGURE 1 | Representation of the experimental setup. Cells were cultured under normoxia for $24 \mathrm{~h}$ in the presence of IFN- $\gamma(5 \mathrm{U} / \mathrm{mL})$ and were infected with $C$. trachomatis (2 IFU/cell) the following day. After $24 \mathrm{~h}$, cells were further incubated under normoxia $\left(20 \% \mathrm{O}_{2}\right)$ or transferred to hypoxic $\left(2 \% \mathrm{O}_{2}\right)$ conditions with constant IFN- $\gamma$ supplementation before samples were collected at the indicated time points. significantly up-regulated IL-6 and IL-8 mRNA expression after 2 and $3 \mathrm{~d}$, respectively (Figures 4A,B). In contrast, IFN- $\gamma$ alone did not (IL-8) or only moderately (IL-6) induce cytokine mRNA expression under hypoxic conditions. Besides, C. trachomatis infection of IFN- $\gamma$ treated cells significantly up-regulated IL-6 (2 and $3 \mathrm{~d})$ and IL- 8 ( $3 \mathrm{~d}$ ) expression compared to IFN- $\gamma$ treated samples under hypoxic conditions. In all cases except for IL-8 in IFN- $\gamma$ treated $C$. trachomatis infected cells after $3 \mathrm{~d}$ and the uninfected and untreated controls, the mRNA expression levels were significantly lower in cells that were incubated under hypoxia compared to normoxia (Figures 4A,B). For IL-1 $\beta$ and MCP-1 no induction of the mRNA expression levels was observed in persistently C. trachomatis infected cells under normoxia, nor reactivated C. trachomatis infection under hypoxia (Figures S1A,B). Our data indicate that in HeLa-229 cells reactivation of formerly persistent $C$. trachomatis in a hypoxic environment is accompanied by a dramatically less pronounced pro-inflammatory host cell immune response compared to persistent Chlamydiae under normoxic conditions.




A



B

$$
2 \mathrm{~d} \quad 3 \mathrm{~d}
$$
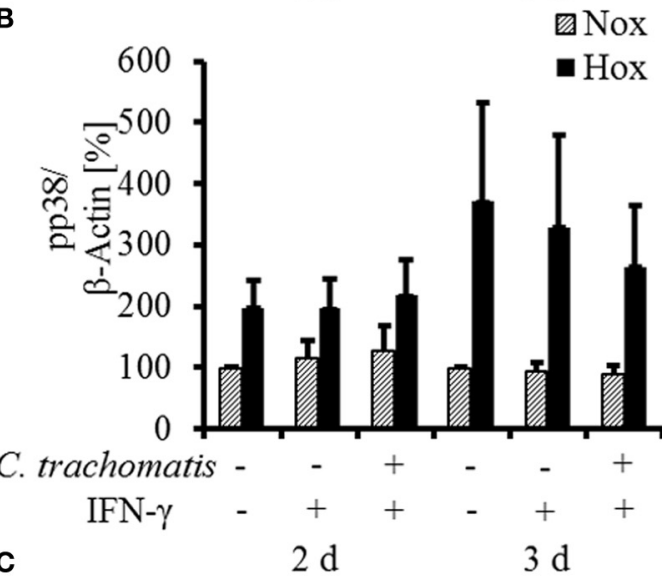

pp44/42

pp38

$\beta$-Actin

C. trachomatis - _ + - + + - + - +

IFN- $\gamma \quad-++-++-+++_{-}+$

\section{Nox Hox Nox Hox $2 \mathrm{~d} \quad 3 \mathrm{~d}$}

FIGURE 3 | Western blot analysis of MAP-kinase phosphorylation in IFN- $\gamma$ treated $C$. trachomatis infected cells under normoxic and hypoxic conditions. Western blot and densitometric analysis of the phosphorylation of the MAP-kinases p44/42 (A) and p38 (B) in IFN- $\gamma$ treated cells after 2 and $3 \mathrm{~d}$ cultivation under normoxic (Nox) and hypoxic (Hox) conditions ( $n=7$, mean \pm s.e.m., ${ }^{*} p \leq 0.05$ ). (C) displays a representative western blot of p38 and p44/42 phosphorylation under normoxic and hypoxic conditions.

\section{DISCUSSION}

Genital tract infections with the intracellular bacteria C. trachomatis are a frequent cause of PID, ectopic pregnancy, and tubal factor infertility (Peipert, 2003). Based on experimental data it is assumed that the infection leads via TLR or NOD1 signaling to an activation of host MAP-kinases (e.g., p44/42 and p38) as well as the NFкB pathway and subsequently to an induction of a pro-inflammatory immune response (Rasmussen et al., 1997;


FIGURE 4 | mRNA expression of IL- 6 and IL-8 in IFN- $\gamma$ treated C. trachomatis infected cells under normoxic and hypoxic conditions. Quantitative analysis of IL-8 (A) and IL-6 (B) mRNA expression in IFN- $\gamma$ treated $C$. trachomatis infected cells after 2 and $3 \mathrm{~d}$ cultivation under normoxic (Nox) and hypoxic (Hox) conditions ( $n=7$, mean \pm s.e.m., $* p \leq 0.05)$

Hanada et al., 2003; Strober et al., 2006; Bastidas et al., 2013; Zhou et al., 2013). A mainly Th1 and NK-cell mediated release of IFN- $\gamma$ protects against genital tract $C$. trachomatis infections in humans and mice (Cohen et al., 2000; Roan and Starnbach, 2006) but may also induce C. trachomatis persistence in vivo (Beatty et al., 1993). Impaired host immunity and micro- environmental conditions such as hypoxia have been shown to impair anti-chlamydial activity of IFN- $\gamma$ leading to reactivation of Chlamydiae and finally productive infection (Roth et al., 2010).

However, nothing is known about the immune response in infected cells during reactivated $C$. trachomatis infection under hypoxic conditions. This is the first report showing that the activation of the MAP-kinase p44/42 and the expression of the pro-inflammatory cytokines IL- 6 and IL- 8 were diminished in reactivated $C$. trachomatis infection under hypoxia compared to persistently infected cells under normoxia. The underlying mechanisms are completely unknown but could either be attributed to oxygen-dependent host-cell signaling pathways or 
linked to pathogen related factors. Under normoxic conditions IFN- $\gamma$ was described to induce IL-6 via activation of $\mathrm{p} 44 / 42$ (Salmenpera et al., 2003). Besides, IFN- $\gamma$ prolongs the activation of p44/42 (Valledor et al., 2008) which augments the induction of IL-6 and IL-8 expression in HeLa-229 cells under normoxic conditions (Yang et al., 2008). Although a strong IFN- $\gamma$ mediated activation of p44/42 and an induction of IL- 6 and IL-8 was detected under normoxic conditions, less phosphorylation or cytokine induction was observed under hypoxic conditions. In accordance with previous results we observed a diminished activity of IFN- $\gamma$ under hypoxia (Roth et al., 2010), which can be explained by the altered p44/42 activation under hypoxic conditions finally leading to a significantly impaired IFN- $\gamma$ driven induction of IL-6 and IL-8.

Furthermore, for productively $C$. trachomatis infected cells it is known that the pathogen directly attaches to the surface of the host cell thereby activating TLR2/4 (Darville et al., 2003; Bulut et al., 2009). In addition, $C$. trachomatis may induce IL-1 $\beta$, IL6 , and IL- 8 by inflammasome-dependent activation of caspase- 1 or NOD1 recognition (Welter-Stahl et al., 2006; Buchholz and Stephens, 2008; Cheng et al., 2008). TLR- and NOD1-mediated signaling has been directly connected to the phosphorylation of MAP-kinase p44/42 (Buchholz and Stephens, 2008; Wortzel and Seger, 2011). Under hypoxic reactivation of persistent Chlamydiae no activation of the p44/42 MAP-kinase was observed, which could explain the diminished IL- 6 and IL- 8 induction under these conditions. It was previously reported that $\mathrm{p} 44 / 42$ could be inactivated by the mitogen-activated protein kinase phosphatase1 (MKP-1), a dual specific phosphatase carrying two hypoxic response elements (HRE) in the promoter region (Liu et al., 2005). Therefore, it has to be further elucidated if hypoxia in general dampens the $\mathrm{p} 44 / 42$ phosphorylation by MKP-1 activation and thereby modulates the immune response and cell homeostasis in a so far unknown manner. There is a tight interconnection between the NFKB and HIF-1 $\alpha$ (hypoxia-inducible factor $1-\alpha)$ signaling pathways in the regulation of inflammatory host responses (Barnes, 1997; Taylor, 2008). Thus, NFкB is activated under hypoxia (Cummins et al., 2006) but in turn also induces transcriptional up-regulation of HIF-1 $\alpha$ expression (Rius et al., 2008). NFKB activation and subsequent pro-inflammatory gene expression is supposed to be abrogated by an enhanced expression of IкB kinase- $\alpha(\mathrm{IKK} \alpha)$ under prolonged hypoxia (Lawrence et al., 2005; Cummins et al., 2006).

Besides the above mentioned host- related factors that may dampen immune responses under hypoxia, additional mechanisms are conceivable, which are directly induced by C. trachomatis. Possible mediators are the chlamydial protease CT441 which might interfere with the NFKB pathway, thereby modulating the immune response and inhibiting the IL-6 and IL- 8 gene expression (Lad et al., 2007a,b). For other intracellular bacteria including Chlamydia pneumoniae (C. pneumoniae), Mycobacterium tuberculosis (M. tuberculosis), and Ehrlichia chaffeensis (E. chaffeensis) several other mechanisms for silencing host immune responses under normoxia have been described. Thus, it has been shown that these bacteria are able to regulate the host immune response by impairing the TLR signaling cascade, blocking the secretion of pro-inflammatory cytokines or induction of anti-inflammatory cytokines such as IL-10 (Ismail et al., 2002;
Flynn and Chan, 2003). M. tuberculosis expresses a $19 \mathrm{kDa}$ protein with immunmodulatory functions that directly binds to the TLR2 receptor and inhibits the IFN- $\gamma$ induced MHC class II antigen presentation, whereas E. chaffeensis was described to interfere with cytokine mRNA stability by an unknown mechanism (Lee and Rikihisa, 1996; Flynn and Chan, 2003). Degradation of the TRAF3 signaling molecule, a downstream target of TLR3, which activates IFN- $\beta$ secretion, was described in $C$. pneumoniae but not in $C$. trachomatis infection (Wolf and Fields, 2013). Nevertheless, C. trachomatis might have similar mechanisms that upon enhanced intracellular replication after hypoxic reactivation results in the down-regulation of host immune responses.

In conclusion, IFN- $\gamma$ induced persistent $C$. trachomatis is reactivated under hypoxic condition and remains mostly unrecognized by the host cell. In further experiments the influence of the impaired activation of the host immune system under hypoxia has to be elucidated in the context of the cellular metabolism and apoptosis signaling. Furthermore, the influence of hypoxia on IFN- $\gamma$ induced persistence has to be clarified in vivo.

\section{AUTHOR CONTRIBUTIONS}

Conception, design of the work: Stefan Jerchel, Jan Rupp; Acquisition of data: Stefan Jerchel, Larissa Schuchardt; Analysis and interpretation: Stefan Jerchel, Jan Rupp, Kensuke Shima, Inga Kaufhold, Larissa Schuchardt; Drafting the manuscript for important intellectual content: Stefan Jerchel, Jan Rupp, Kensuke Shima, Inga Kaufhold; Final approval of the version to be published: Stefan Jerchel, Jan Rupp, Kensuke Shima, Inga Kaufhold, Larissa Schuchardt; Agreement to be accountable for all aspects of the work: Stefan Jerchel, Jan Rupp, Inga Kaufhold, Kensuke Shima, Larissa Schuchardt.

\section{ACKNOWLEDGMENTS}

This work was funded by the DFG Cluster of Excellence "Inflammation at Interfaces" and the University of Lübeck (SPP MIA/TP A2). We grateful thank A. Gravenhorst, A. Hellberg, S. Pätzmann, and K. Wischnat for excellent technical assistance.

\section{SUPPLEMENTARY MATERIAL}

The Supplementary Material for this article can be found online at: http://www.frontiersin.org/journal/10.3389/fcimb. 2014.00043/abstract

Figure S1 | mRNA expression of MCP-1 and IL- $\beta$ in IFN- $\gamma$ treated C. trachomatis infected cells under normoxic and hypoxic conditions. Quantitative analysis of MCP-1 (A) and IL-1 $\beta$ (B) mRNA expression in IFN- $\gamma$ treated $C$. trachomatis infected cells after 2 and 3 d cultivation under normoxic (Nox) and hypoxic (Hox) conditions ( $n=7$, mean \pm s.e.m., $* p \leq 0.05)$.

\section{REFERENCES}

Barnes, P. J. (1997). Nuclear factor-kappa B. Int. J. Biochem. Cell Biol. 29, 867-870. doi: 10.1016/S1357-2725(96)00159-8

Bastidas, R. J., Elwell, C. A., Engel, J. N., and Valdivia, R. H. (2013). Chlamydial intracellular survival strategies. Cold Spring Harb. Perspect. Med. 3:a010256. doi: 10.1101/cshperspect.a010256

Beatty, W. L., Belanger, T. A., Desai, A. A., Morrison, R. P., and Byrne, G. I. (1994). Tryptophan depletion as a mechanism of gamma interferon-mediated chlamydial persistence. Infect. Immun. 62, 3705-3711. 
Beatty, W. L., Byrne, G. I., and Morrison, R. P. (1993). Morphologic and antigenic characterization of interferon gamma-mediated persistent Chlamydia trachomatis infection in vitro. Proc. Natl. Acad. Sci. U.S.A. 90, 3998-4002. doi: 10.1073/pnas.90.9.3998

Buchholz, K. R., and Stephens, R. S. (2007). The extracellular signal-regulated kinase/mitogen-activated protein kinase pathway induces the inflammatory factor interleukin-8 following Chlamydia trachomatis infection. Infect. Immun. 75, 5924-5929. doi: 10.1128/IAI.01029-07

Buchholz, K. R., and Stephens, R. S. (2008). The cytosolic pattern recognition receptor NOD1 induces inflammatory interleukin-8 during Chlamydia trachomatis infection. Infect. Immun. 76, 3150-3155. doi: 10.1128/IAI.00104-08

Bulut, Y., Shimada, K., Wong, M. H., Chen, S., Gray, P., Alsabeh, R., et al. (2009). Chlamydial heat shock protein 60 induces acute pulmonary inflammation in mice via the Toll-like receptor 4- and MyD88-dependent pathway. Infect. Immun. 77, 2683-2690. doi: 10.1128/IAI.00248-09

Centers for Disease Control and Prevention. (2012). 2011 Sexually Transmitted Disease Surveillance. Atlanta: U.S. Department of Health and Human Services, Devision of STD Prevention.

Cheng, W., Shivshankar, P., Li, Z., Chen, L., Yeh, I. T., and Zhong, G. (2008). Caspase-1 contributes to Chlamydia trachomatis-induced upper urogenital tract inflammatory pathologies without affecting the course of infection. Infect. Immun. 76, 515-522. doi: 10.1128/IAI.01064-07

Cohen, C. R., Nguti, R., Bukusi, E. A., Lu, H., Shen, C., Luo, M., et al. (2000). Human immunodeficiency virus type 1-infected women exhibit reduced interferon-gamma secretion after Chlamydia trachomatis stimulation of peripheral blood lymphocytes. J. Infect. Dis. 182, 1672-1677. doi: 10.1086/ 317616

Cummins, E. P., Berra, E., Comerford, K. M., Ginouves, A., Fitzgerald, K. T., Seeballuck, F., et al. (2006). Prolyl hydroxylase-1 negatively regulates IkappaB kinase-beta, giving insight into hypoxia-induced NFkappaB activity. Proc. Natl. Acad. Sci. U.S.A. 103, 18154-18159. doi: 10.1073/pnas.0602235103

Darville, T., O’Neill, J. M., Andrews, C. W. Jr., Nagarajan, U. M., Stahl, L., and Ojcius, D. M. (2003). Toll-like receptor-2, but not Toll-like receptor-4, is essential for development of oviduct pathology in chlamydial genital tract infection. J. Immunol. 171, 6187-6197.

Dean, D., Suchland, R. J., and Stamm, W. E. (2000). Evidence for long-term cervical persistence of Chlamydia trachomatis by ompl genotyping. J. Infect. Dis. 182, 909-916. doi: 10.1086/315778

Flynn, J. L., and Chan, J. (2003). Immune evasion by Mycobacterium tuberculosis: living with the enemy. Curr. Opin. Immunol. 15, 450-455. doi: 10.1016/S09527915(03)00075-X

Geisler, W. M. (2007). Management of uncomplicated Chlamydia trachomatis infections in adolescents and adults: evidence reviewed for the 2006 Centers for Disease Control and Prevention sexually transmitted diseases treatment guidelines. Clin. Infect. Dis. 44(Suppl. 3), S77-S83. doi: 10. 1086/511421

Golden, M. R., Whittington, W. L., Handsfield, H. H., Hughes, J. P., Stamm, W. E., Hogben, M., et al. (2005). Effect of expedited treatment of sex partners on recurrent or persistent gonorrhea or chlamydial infection. N. Engl. J. Med. 352, 676-685. doi: 10.1056/NEJMoa041681

Hanada, H., Ikeda-Dantsuji, Y., Naito, M., and Nagayama, A. (2003). Infection of human fibroblast-like synovial cells with Chlamydia trachomatis results in persistent infection and interleukin-6 production. Microb. Pathog. 34, 57-63. doi: 10.1016/S0882-4010(02)00189-4

Hogan, R. J., Mathews, S. A., Mukhopadhyay, S., Summersgill, J. T., and Timms, P. (2004). Chlamydial persistence: beyond the biphasic paradigm. Infect. Immun. 72, 1843-1855. doi: 10.1128/IAI.72.4.1843-1855.2004

Hvid, M., Baczynska, A., Deleuran, B., Fedder, J., Knudsen, H. J., Christiansen, G., et al. (2007). Interleukin-1 is the initiator of Fallopian tube destruction during Chlamydia trachomatis infection. Cell Microbiol. 9, 2795-2803. doi: 10.1111/j.1462-5822.2007.00996.x

Ismail, N., Olano, J. P., Feng, H. M., and Walker, D. H. (2002). Current status of immune mechanisms of killing of intracellular microorganisms. FEMS Microbiol. Lett. 207, 111-120. doi: 10.1111/j.1574-6968.2002.tb11038.x

Lad, S. P., Li, J., da Silva, C. J., Pan, Q., Gadwal, S., Ulevitch, R. J., et al. (2007a). Cleavage of p65/RelA of the NF-kappaB pathway by Chlamydia. Proc. Natl. Acad. Sci. U.S.A. 104, 2933-2938. doi: 10.1073/pnas.0608393104

Lad, S. P., Yang, G., Scott, D. A., Wang, G., Nair, P., Mathison, J., et al. (2007b). Chlamydial CT441 is a PDZ domain-containing tail-specific protease that interferes with the NF-kappaB pathway of immune response. J. Bacteriol. 189, 6619-6625. doi: 10.1128/JB.00429-07

Lawrence, T., Bebien, M., Liu, G. Y., Nizet, V., and Karin, M. (2005). IKKalpha limits macrophage NF-kappaB activation and contributes to the resolution of inflammation. Nature 434, 1138-1143. doi: 10.1038/nature03491

Lee, E. H., and Rikihisa, Y. (1996). Absence of tumor necrosis factor alpha, interleukin-6 (IL-6), and granulocyte-macrophage colony-stimulating factor expression but presence of IL-1beta, IL-8, and IL-10 expression in human monocytes exposed to viable or killed Ehrlichia chaffeensis. Infect. Immun. 64, 4211-4219.

Liu, C., Shi, Y., Du, Y., Ning, X., Liu, N., Huang, D., et al. (2005). Dualspecificity phosphatase DUSP1 protects overactivation of hypoxia-inducible factor 1 through inactivating ERK MAPK. Exp. Cell Res. 309, 410-418. doi: 10.1016/j.yexcr.2005.06.022

Livak, K. J., and Schmittgen, T. D. (2001). Analysis of relative gene expression data using real-time quantitative PCR and the 2(-Delta Delta C(T)) Method. Methods 25, 402-408. doi: 10.1006/meth.2001.1262

Mardh, P. A. (2004). Tubal factor infertility, with special regard to chlamydial salpingitis. Curr. Opin. Infect. Dis. 17, 49-52. doi: 10.1097/00001432-20040200000010

Peipert, J. F. (2003). Clinical practice. Genital chlamydial infections. N. Engl. J. Med. 349, 2424-2430. doi: 10.1056/NEJMcp030542

Phillips, C. R., Kintner, J., Whittimore, J., and Schoborg, R. V. (2012). Chlamydia muridarum enters a viable but non-infectious state in amoxicillintreated BALB/c mice. Microbes Infect. 14, 1177-1185. doi: 10.1016/j.micinf. 2012.07.017

Rasmussen, S. J., Eckmann, L., Quayle, A. J., Shen, L., Zhang, Y. X., Anderson, D. J., et al. (1997). Secretion of proinflammatory cytokines by epithelial cells in response to Chlamydia infection suggests a central role for epithelial cells in chlamydial pathogenesis. J. Clin. Invest 99, 77-87. doi: 10.1172/ JCI119136

Reveneau, N., Crane, D. D., Fischer, E., and Caldwell, H. D. (2005). Bactericidal activity of first-choice antibiotics against gamma interferon-induced persistent infection of human epithelial cells by Chlamydia trachomatis. Antimicrob. Agents Chemother. 49, 1787-1793. doi: 10.1128/AAC.49.5.1787-1793.2005

Rius, J., Guma, M., Schachtrup, C., Akassoglou, K., Zinkernagel, A. S., Nizet, V., et al. (2008). NF-кB links innate immunity to the hypoxic response through transcriptional regulation of HIF-1 $\alpha$. Nature 453, 807-811. doi: 10.1038/nature06905

Roan, N. R., and Starnbach, M. N. (2006). Antigen-specific CD8+ T cells respond to Chlamydia trachomatis in the genital mucosa. J. Immunol. 177, 7974-7979.

Roth, A., Konig, P., van Zandbergen, G., Klinger, M., Hellwig-Burgel, T., Daubener, W., et al. (2010). Hypoxia abrogates antichlamydial properties of IFN-gamma in human fallopian tube cells in vitro and ex vivo. Proc. Natl. Acad. Sci. U.S.A. 107, 19502-19507. doi: 10.1073/pnas.1008178107

Salmenpera, P., Hamalainen, S., Hukkanen, M., and Kankuri, E. (2003). Interferongamma induces C/EBP beta expression and activity through MEK/ERK and p38 in T84 colon epithelial cells. Am. J. Physiol. Cell Physiol. 284, C1133-C1139. doi: 10.1152/ajpcell.00293.2002

Shima, K., Klinger, M., Solbach, W., and Rupp, J. (2013). Activities of firstchoice antimicrobials against gamma interferon-treated Chlamydia trachomatis differ in hypoxia. Antimicrob. Agents Chemother. 57, 2828-2830. doi: 10.1128/AAC.02211-12

Strober, W., Murray, P. J., Kitani, A., and Watanabe, T. (2006). Signalling pathways and molecular interactions of NOD1 and NOD2. Nat. Rev. Immunol. 6, 9-20. doi: $10.1038 /$ nri1747

Taylor, C. T. (2008). Interdependent roles for hypoxia inducible factor and nuclear factor-kappaB in hypoxic inflammation. J. Physiol. 586, 4055-4059. doi: 10.1113/jphysiol.2008.157669

Valledor, A. F., Arpa, L., Sanchez-Tillo, E., Comalada, M., Casals, C., Xaus, J., et al. (2008). IFN- $\{\gamma\}$-mediated inhibition of MAPK phosphatase expression results in prolonged MAPK activity in response to M-CSF and inhibition of proliferation. Blood 112, 3274-3282. doi: 10.1182/blood-200711-123604

Welter-Stahl, L., Ojcius, D. M., Viala, J., Girardin, S., Liu, W., Delarbre, C., et al. (2006). Stimulation of the cytosolic receptor for peptidoglycan, Nod1, by infection with Chlamydia trachomatis or Chlamydia muridarum. Cell Microbiol. 8, 1047-1057. doi: 10.1111/j.1462-5822.2006. 00686.x 
Wolf, K., and Fields, K. A. (2013). Chlamydia pneumoniae impairs the innate immune response in infected epithelial cells by targeting TRAF3. J. Immunol. 190, 1695-1701. doi: 10.4049/jimmunol.1202443

Wortzel, I., and Seger, R. (2011). The ERK cascade: distinct functions within various subcellular organelles. Genes Cancer 2, 195-209. doi: 10.1177/1947601911407328

Wyrick, P. B. (2010). Chlamydia trachomatis persistence in vitro: an overview. J. Infect. Dis. 201(Suppl. 2), S88-S95. doi: 10.1086/652394

Yang, H. T., Cohen, P., and Rousseau, S. (2008). IL-1beta-stimulated activation of ERK1/2 and p38alpha MAPK mediates the transcriptional up-regulation of IL-6, IL-8 and GRO-alpha in HeLa cells. Cell Signal. 20, 375-380. doi: 10.1016/j.cellsig.2007.10.025

Zhou, H., Huang, Q., Li, Z., Wu, Y., Xie, X., Ma, K., et al. (2013). PORF5 plasmid protein of Chlamydia trachomatis induces MAPKmediated pro-inflammatory cytokines via TLR2 activation in THP-1 cells. Sci. China Life Sci. 56, 460-466. doi: 10.1007/s11427013-4470-8
Conflict of Interest Statement: The authors declare that the research was conducted in the absence of any commercial or financial relationships that could be construed as a potential conflict of interest.

Received: 07 February 2014; accepted: 25 March 2014; published online: 16 April 2014. Citation: Jerchel S, Kaufhold I, Schuchardt L, Shima K and Rupp J (2014) Host immune responses after hypoxic reactivation of IFN- $\boldsymbol{\gamma}$ induced persistent Chlamydia trachomatis infection. Front. Cell. Infect. Microbiol. 4:43. doi: 10.3389/ fcimb.2014.00043

This article was submitted to the journal Frontiers in Cellular and Infection Microbiology.

Copyright (C) 2014 Jerchel, Kaufhold, Schuchardt, Shima and Rupp. This is an openaccess article distributed under the terms of the Creative Commons Attribution License (CC BY). The use, distribution or reproduction in other forums is permitted, provided the original author(s) or licensor are credited and that the original publication in this journal is cited, in accordance with accepted academic practice. No use, distribution or reproduction is permitted which does not comply with these terms. 